\title{
Three Distinct Axonal Transport Rates for Tau, Tubulin, and Other Microtubule-Associated Proteins: Evidence for Dynamic Interactions of Tau with Microtubules in vivo
}

\author{
M. Mercken, ${ }^{1,2}$ I. Fischer,${ }^{3}$ K. S. Kosik, ${ }^{4}$ and R. A. Nixon ${ }^{1,2}$ \\ 'Laboratories for Molecular Neuroscience, Mailman Research Center, McLean Hospital, Belmont, Massachusetts \\ 02178, '2Department of Psychiatry, Harvard Medical School, Boston, Massachusetts 02115, ${ }^{3}$ Department of \\ Anatomy and Neurobiology, Medical College of Pennsylvania, Philadelphia, Pennsylvania 19129, and ${ }^{1}$ Department \\ of Neurology, Brigham and Women's Hospital, Harvard Medical School, Boston, Massachusetts 02115
}

Microtubule-associated proteins (MAPs), such as tau, modulate neuronal shape and process outgrowth by influencing the stability and organization of microtubules. The dynamic nature of MAP-microtubule interactions in vivo, however, is poorly understood. Here, we have assessed the stability of these interactions by investigating the synthesis and axoplasmic transport of tau in relation to that of tubulin and other MAPs within retinal ganglion cells of normal adult mice in vivo. Using immunoprecipitation and Western blot analysis with anti-tau monoclonal and polyclonal antibodies, we unequivocally identified in optic axons a family of 50-60 kDa tau isoforms and a second 90$95 \mathrm{kDa}$ tau family, the members of which were shown to contain the domain of tau encoded by exon 4A. To measure the rates of translocation of tau proteins in vivo, we injected mice with ${ }^{35}$ S-methionine intravitreously and, after 6-30 d, quantitated the radiolabeled tau isoforms immunoprecipitated from eight consecutive $1.1 \mathrm{~mm}$ segments of the nerve and optic tract and separated by electrophoresis. Linear regression analysis of protein transport along optic axons showed that the tau isoforms advanced at a rate of $0.2-0.4 \mathrm{~mm} / \mathrm{d}$, and other radiolabeled MAPs, identified by their association with taxol-stabilized microtubules, moved three- to fivefold more rapidly. By contrast, tubulins advanced at $0.1-0.2 \mathrm{~mm} / \mathrm{d}$, significantly more slowly than tau or other MAPs. These studies establish that tau is not cotransported with tubulin or microtubules, indicating that associations of tau with microtubules within axons are not as stable as previously believed. Our findings also reveal differences among various MAPs in their interactions with microtubules and provide evidence that assembly and reorganization of the microtubule network is an active process even after axons establish connections and fully mature.

[Key words: retinal ganglion cells, axons, neurons,

\footnotetext{
Received May 31, 1995; revised Aug. 18, 1995; accepted Aug. 21, 1995.

These studies were supported by NIA Grant AG05604 and NIH Grant NS24725. We are grateful to Johanne Khan for help in preparing the manuscript and to Kate Nixon for artwork. We also thank Dr. Lester Binder for generously providing the tau-I antibody and Dr. Mathew Suffness of the National Cancer Institute for providing taxol.

Correspondence should be addressed to Ralph A. Nixon, Ph.D., M.D., Laboratories for Molecular Neuroscience, Mailman Research Center, McLean Hospital, 115 Mill Street, Belmont, MA 02178.

Copyright $\subset 1995$ Society for Neuroscience $0270-6474 / 95 / 158259-09 \$ 05.00 / 0$
}

mouse, cytoskeleton, Alzheimer's disease, neurofibrillary tangles]

Microtubules assembled in vitro or in living cells retain the ability to switch continuously between phases of growth and shrinkage, endowing them with the necessary plasticity to serve diverse roles in different parts of the cell. Spatial and temporal control of this process, termed dynamic instability (Mitchison and Kirschner, 1984), predicts that posttranslational mechanisms exist for this purpose and might be especially prominent in cells with highly polar shapes, like neurons. Not surprisingly, families of proteins have been identified in brain which copurify with microtubules through repeated cycles of tubulin assembly and disassembly and influence the stability of microtubule assemblies (Murphy and Borisy, 1975; Sloboda et al., 1976). A high molecular weight group of microtubule-associated proteins is represented most abundantly by MAP1A (340 kDa), MAP 1B (320 kDa), and two closely related MAP2 isoforms, MAP2A and MAP2B (both $280 \mathrm{kDa}$ ) (for review, Matus, 1988, 1991; Tucker, 1990; Olmsted, 1991; Wiche et al., 1991; Hirokawa, 1994). A second group of lower molecular weight MAPs, designated tau, consists of a set of four polypeptides migrating in SDS-PAGE between $55 \mathrm{kDa}$ and $62 \mathrm{kDa}$ (Weingarten et al., 1975; Cleveland et al., 1977a,b). In certain neuron types, additional tau isoforms arise by alternative splicing of the single primary transcript, including a microheterogeneous group of about $110 \mathrm{kDa}$ (high molecular weight tau or HMW tau) (Drubin et al., 1985; Peng et al., 1986; Georgieff et al., 1991; Oblinger et al., 1991; Shea et al., 1992) and another group of about 90$100 \mathrm{kDa}$ (middle molecular weight tau or MMW tau) (Taleghany and Oblinger, 1992). The finding that tau proteins are the major structural components of neurofibrillary tangles, a pathological hallmark of Alzheimer disease, has stimulated intense interest in their molecular and cell biology (for reviews, Goedert, 1993; Mandelkow and Mandelkow, 1993; Kosik, 1993).

Tau and certain other MAPs are believed to influence the microtubule network in various ways. Tau increases the polymerization rate of individual microtubules and slows their rate of depolymerization (Drechsel et al., 1992), thereby favoring microtubule elongation and, possibly, nucleation (Brandt and Lee, 1993). Microtubules stabilized by tau, MAP2C, or MAP1B, are more stable in response to microtubule depolymerizing agents (Takemura et al., 1992). By binding adjacent tubulin subunits in the microtubule wall through their repeated tubulin binding mo- 
tifs, tau and other MAPs may restrict the flexibility of the microtubule (Matus, 1994). Finally, projections of certain MAPs from the microtubule surface may promote bundling (Kanai et al., 1989; Scott et al., 1992) or even interconnect microtubules and neurofilaments (Leterrier et al., 1982; Aamodt and Williams, 1984; Hirokawa et al., 1988a) and confer a distinctive lateral spacing to the microtubule network (Chen et al., 1992). By thus promoting microtubule stabilization, elongation, and rigidification, tau and other MAPs transform microtubules into long structural support elements suitable for one of their important roles as a key determinant of axonal caliber in the CNS (Friede and Samorajski, 1970; Saitua and Alvarez, 1988; Sakaguchi et al., 1993; Nixon et al., 1994).

One approach to understanding the functions and dynamic behaviors of tau and other MAPs in vivo has been to pulse-label them in neurons with radioactive amino acids, and to relate their kinetics of movement along axons to those of other potentially interactive proteins. Using this approach, Tytell et al. (1984) observed that several labeled proteins believed to be tau proteins migrated along axons at the same rate as radiolabeled tubulin in the slowest phase of axonal transport. These findings were interpreted as evidence for a highly stable association of tau with microtubules and as support for the hypothesis that this association reflects the axonal transport of highly stable microtubules. This picture of MAP and microtubule in vivo interactions, however, diverges from the more dynamic image emerging from in vitro assembly analyses (Olmsted et al., 1989; Brugg and Matus, 1991; Correas et al., 1992; Hirokawa, 1994) and cultured cell studies (Scherson et al., 1984; Olmsted et al., 1989) including recent studies of growing neurons in culture, which show, by different experimental approaches (Okabe and Hirokawa, 1988; Baas and Black, 1990; Ahmad et al., 1993) that at least a portion of an axonal microtubule is labile and able to exchange or add tubulin subunits.

In this study, we reinvestigated the in vivo dynamics of tau proteins by characterizing their axonal transport in retinal ganglion cells of normal adult mice using monoclonal and polyclonal antibodies to confirm the identities of MMW and LMW tau isoforms in optic axons. For comparison, we also studied the transport of tubulin and individual members of a family of proteins that coassemble with tubulin during microtubule assembly. By establishing that tau proteins are transported at a rate distinct from the rates of movement of tubulin and other microtubule-associated proteins, we demonstrate previously unrecognized dynamic behavior of tau-microtubule interactions in mature neurons in vivo.

\section{Materials and Methods}

Isotope injections. Radiolabeled amino acids were injected intravitreously into anesthetized male and female $\mathrm{C} 57 \mathrm{Bl} / 6 \mathrm{~J}$ mice, aged 10-14 weeks, as previously described (Nixon, 1980). Mice received $0.25 \mu \mathrm{l}$ of phosphate buffered normal saline which contained $50-100 \mu \mathrm{Ci}$ of $\mathrm{L}^{-35} \mathrm{~S}$-methionine (specific activity $1000 \mathrm{Ci} / \mathrm{mmol}$ ) purchased from $\mathrm{Du}$ Pont-New Englard Nuclear (Boston, MA).

Tissue preparations. Mice were killed by cervical dislocation. After the brain was removed and cooled, the optic nerve and optic tract were freed from meninges and the optic tract on each side was severed at a point $2.5 \mathrm{~mm}$ from the superior colliculus. This dissected length of optic pathway was $9 \mathrm{~mm}$ long and consisted of the optic nerves severed at the scleral surface of the eye, the optic chiasm, and a length of the optic tract extending to, but not including, terminals in the lateral geniculate nucleus. For the transport studies, the optic pathway was cut into eight consecutive $1.1 \mathrm{~mm}$ segments on a micrometer slide. For each timepoint, the optic pathways from 30 mice were used and all manipulations were performed at $4^{\circ} \mathrm{C}$.
Cytoskeleton and heat-stable supernatant preparations. Cytoskeletal proteins and Triton $\mathrm{X}-100$-soluble fractions were prepared from optic axons by the method of Chiu and Norton (1982) in $50 \mathrm{~mm}$ Tris- $\mathrm{HCl}$, pII 7.5, $150 \mathrm{~mm} \mathrm{NaCl}$ (TBS) containing $1 \%$ Triton X-100 and the protease inhibitors leupeptin $(50 \mu \mathrm{g} / \mathrm{ml})$, PMSF ( $1 \mathrm{mM})$, and aprotinin (2 $\mu \mathrm{g} / \mathrm{ml}$ ). Heat-stable supernatant fractions were obtained after boiling the Triton X-100-soluble fractions for $10 \mathrm{~min}$ and centrifugation at 15,000 r.p.m. for $20 \mathrm{~min}$ at $4^{\circ} \mathrm{C}$.

Antibodies. Monoclonal antibodies tau-1 and 5E2 were used for immunoprecipitation and have been extensively characterized elsewhere (Binder et al., 1985; Dotti et al., 1987; Joachim et al., 1987; Kosik et al., 1988). The polyclonal anti-tau antiserum (LK) was produced in rabbit against affinity purified mouse tau, prepared as described elsewhere (Mercken et al., 1992), except that the tau-1 monoclonal antibody was used for the preparation of the affinity column.

Immunoprecipitation of tau proteins. Protein G-Sepharose (Pharmacia) was incubated for $1 \mathrm{hr}$ at room temperature with a cocktail of the monoclonal antibodies 5E2 and tau-1. The gel was washed with TBSTriton to remove unbound antibodies and incubated with shaking for 3 hr with heat-stable supernatants containing radiolabeled tau proteins. After a thorough wash with TBS-Triton, the immunoprecipitated proteins were eluted from the gel by boiling in $200 \mu \mathrm{l}$ of electrophoresis sample buffer for $5 \mathrm{~min}$.

PAGE and immunoblot analysis. SDS-PAGE was carried out by the method of Laemmli (1970) using $320 \mathrm{~mm}$ slab gels containing 5-15\% polyacrylamide gradients (Nixon et al., 1982). Proteins separated by SDS-PAGE were electrophoretically transferred to nitrocellulose membrane (Millipore, Bedford, MA) for 2 hr at $110 \mathrm{~V}$ in Tris/glycine buffer $\mathrm{pH} 8.3$ with $20 \%$ methanol. The nitrocellulose was incubated at room temperature in TBS containing 5\% nonfat dry milk to block nonspecific binding. The nitrocellulose was then reacted overnight at $4^{\circ} \mathrm{C}$ with the primary antibodies diluted in the same solution. After washing with TBS containing $0.05 \%$ Tween-20, the membrane was incubated with horseradish peroxidase-conjugated antibodies for $2 \mathrm{hr}$ at room temperature, washed, and stained with diaminobenzidine.

Taxol microtubule preparations. The microtubule fraction from segments of at least 10 individual radiolabeled optic nerves was prepared using the taxol method (Vallee, 1982). The tissue was homogenized in 1.5 vol of MT buffer ( $50 \mathrm{~mm}$ PIPES, pH 6.6, $1 \mathrm{~mm} \mathrm{MgSO}_{4}, 1 \mathrm{~mm}$ EGTA), including protease inhibitors, and centrifuged at $100,000 \times g$ for $30 \mathrm{~min}$. The supernatant was adjusted to contain $1 \mathrm{~mm}$ GTP and 10 $\mu \mathrm{M}$ taxol, incubated at $37^{\circ} \mathrm{C}$ to polymerize the microtubules and centrifuged at $40,000 \times \mathrm{g}$. The pellet containing the microtubule fraction was used for SDS-PAGE analysis and autoradiography as described in other sections.

Autoradiography and densitometry. Tau protcins wcrc immunoprecipitated, separated on SDS-PAGE and transferred to nitrocellulose as described above. The nitrocellulose was dried and exposed to Kodak X-OMAT XAR-5 film for autoradiography. Membranes were rewetted in TBS after exposure and processed for immunoblotting.

Triton X-100-insoluble pellets or taxol microtubule pellets were solubilized in sample buffer and separated by SDS-PAGE as described above. The gels were dried and exposed for autoradiography. Scanning of autoradiograms was performed with the Apple Color OneScanner and data were processed with SCAN ANALYSIS software (Biosoft).

Statistical analysis. Standard errors for the slopes in the regression analysis of the peak values for tau, tubulin and MAP1A were calculated by using SAS software (SAS Institute Inc., Cary, NC). $t$ tests were performed to determine that the $99 \%$ confidence intervals for the slopes were not overlapping. The transport ranges cited in the text are based on the slope values and their $99 \%$ confidence interval.

\section{Results}

\section{Identification of tau isoforms in retinal ganglion cell axons}

'lo relate the different tau isoforms in optic axons to those of tau proteins expressed in other neurons, we compared heat-stable preparations from different neuronal tissues by immunoblot analysis using a polyclonal antiserum raised to purified mouse tau (Fig. 1). The optic pathway contained several tau isoforms in the $50-60 \mathrm{kDa}$ range, the most prominent of which correspond to the three major low molecular weight tau (LMW tau) isoforms present in mouse brain and an additional series of bands in the 90-95 $\mathrm{kDa}$ range previously described (Taleghany 




Figure 1. Immunoblot analysis of tau isoforms in different nervous tissue regions from adult mice. Lanes contain heat stable extracts of each region separated by $5-15 \%$ SDS-PAGE and immunoblotted with the polyclonal rabbit anti-tau antiserum (LK, 1/1000; lanes 1-5) or the monoclonal antibody tau-1 (lane 6). Note the high amounts of MMWtau $(95 \mathrm{kDa})$ present in the optic nerve and the presence of three major LMW tau isoforms in brain.

and Oblinger, 1992) as medium molecular weight forms of tau (MMW tau). The similar intensity of the bands in the immunoblots suggests that the LMW tau and MMW tau isoforms are present in approximately equal amounts in optic axons, but in the retina MMW tau is underrepresented. In addition a very small amount of the high molecular weight tau (HMW tau) isoforms at $105-110 \mathrm{kDa}$ were detected in the optic nerve. The spinal cord shows the complete mixture of LMW tau, MMW tau, and HMW tau. Only the latter group of tau isoforms was detectable in heat-stable extracts from the sciatic nerve. The high sensitivity of the polyclonal antibody also allowed the detection of the very low amounts of HMW tau and MMW tau isoforms (Fig. 1, lane 5) that are present in total brain extract (Taleghany and Oblinger, 1992) and that are not detected by the tau-1 antibody under the conditions used here (Fig. 1, lane 6).

\section{Axoplasmic transport of tau proteins in mouse retinal ganglion cells}

To determine their rate of axoplasmic transport along optic axons, tau proteins were pulse-radiolabeled by injecting adult C57/ $\mathrm{Bl}$ mice intravitreously with ${ }^{35} \mathrm{~S}$-methionine. At various intervals after isotope injection, optic pathways were dissected from mice and cut into eight consecutive $1.1 \mathrm{~mm}$ segments. Using a mix-

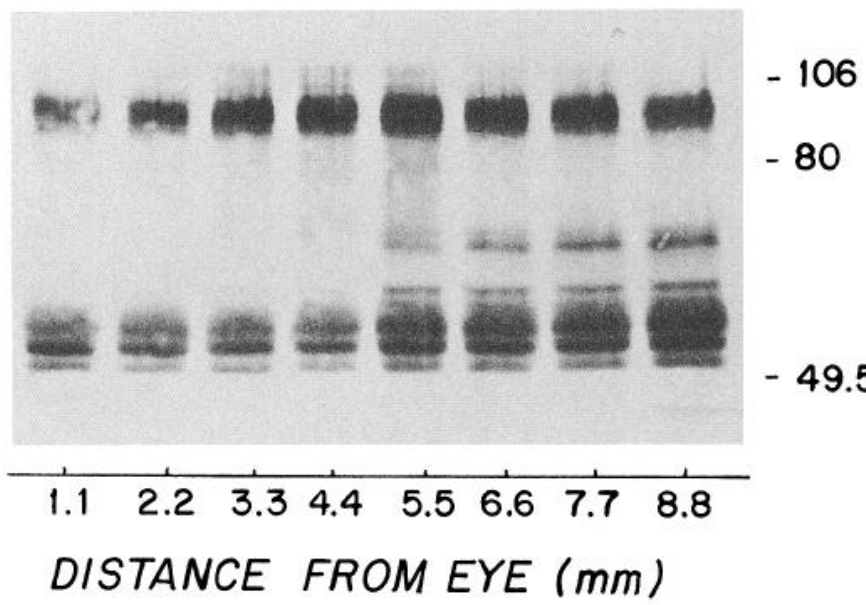

Figure 2. Tau proteins immunoprecipitated from heat stable extracts from eight consecutive segments of the optic pathway. After immunoprecipitation with the monoclonal antibodies 5E2 and tau-1, the proteins were separated by $5-15 \%$ SDS-PAGE, transferred to nitrocellulose membranes, and stained with the polyclonal rabbit anti-tau antiserum (LK, 1/1000).

ture of two monoclonal antibodies (tau-1 and 5E2), we immunoprecipitated tau proteins from heat-stable supernatant fractions prepared from the eight individual optic nerve segments each pooled from 20-30 mice. The identity of tau as a major immunoprecipitated protein was verified by immunoblot analysis with polyclonal tau antiserum (Fig. 2). Comparison of the immunoprecipitated tau isoforms with the group present in unfractionated tissue indicated that the tau proteins were quantitatively immunoprecipitated. Densitometric analysis of immunoreactivity signals in the supernatant and pellet fractions after immunoprecipitation showed that $96 \%$ of the tau immunoreactivity was in the immunoprecipitate. As observed in unfractionated optic axons (Fig. 1), both LMW and MMW tau isoforms were present in approximately equal amounts. This ratio was evident in segments 2-7 of the optic pathway, but a higher ratio of LMW isoforms to MMW isoforms was consistently seen in the most proximal and distal axon segments. Traces of underlying brain tissue, which contain mostly LMW tau isoforms, may adhere to the most distal portions of the optic tract and conceivably may contribute to the enrichment of LMW tau in segment 8; however, the lower ratio of MMW to LMW tau at very proximal optic axon levels reflects a different organization of the axonal cytoskeleton in this region, as previously noted (Nixon et al, 1994). The absence of a shift in apparent molecular weight for the different tau isoforms in the eight consecutive segments suggests no extreme differences in the phosphorylation state of the total pool of tau proteins along optic axons.

By comparing the distribution of ${ }^{35} \mathrm{~S}$-methionine labeled tau proteins in the eight optic segments on autoradiographs of tauimmunoprecipitates prepared at different timepoints after injection, we could demonstrate the progressive movement of the pulse-labeled tau along optic axons (Fig. 3). At all timepoints, both LMW and MMW tau proteins moved coordinately. By day 7 after isotope injection, the peak of the radioactive tau wave had moved a distance of $2.2 \mathrm{~mm}$, and by 15 days, a distance of $4.9 \mathrm{~mm}$, indicating a transport velocity of $0.2-0.4 \mathrm{~mm} / \mathrm{d}$ (Fig. $3 A$ ). The tau transport wave continued to move distalward over time. The distance traveled by $22 \mathrm{~d}$ and $30 \mathrm{~d}$ after injection 


\section{DAYS}

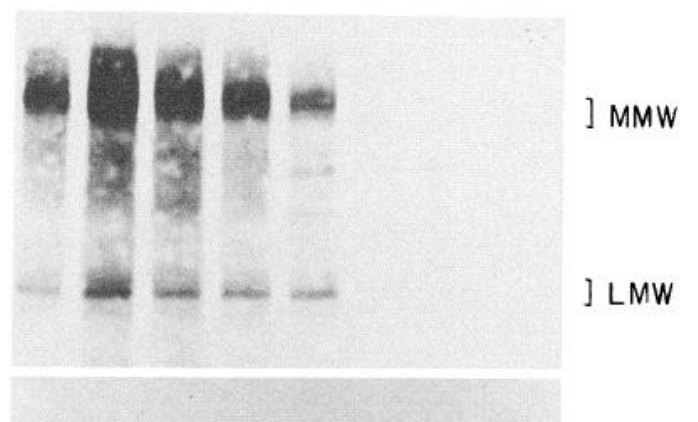

15 DAYS

] $\mathrm{MMW}$

] LMW

\section{DAYS}

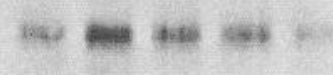

] $\mathrm{MMW}$

] LMW

\section{DAYS}

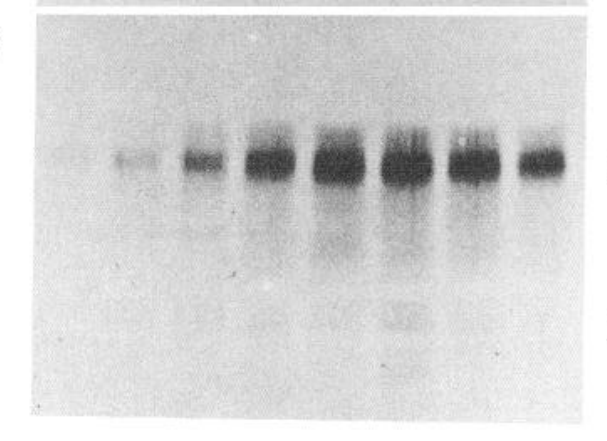

] $\mathrm{MMW}$

\section{$\begin{array}{lllllllll}1.1 & 2.2 & 3.3 & 4.4 & 5.5 & 6.6 & 7.7 & 8.8\end{array}$ DISTANCE FROM EYE ( $\mathrm{mm})$}

Figure 3. Distribution of radiolabeled tau along eight consecutive 1.1 mm segments of the optic nerve and tract at 7,15,22, and $30 \mathrm{~d}$ after injecting mice with ${ }^{35} \mathrm{~S}$-methionine. For each time point, tau was immunoprecipitated from heat stable extracts prepared from each segment, subjected to 5-15\% SDS-PAGE and blotted to nitrocellulose membranes. Radiolabeled proteins were visualized by autoradiography.

suggested that tau transport may slow slightly at distal axonal levels.

The radioactivity in LMW isoforms relative to that in MMW isoforms was consistently lower than the ratio of the corresponding immunostained proteins detected on the same immunoblots with anti-tau antibodies. Possible explanations for the lower relative incorporation of ${ }^{35} \mathrm{~S}$ label into LMW tau may include a smaller number of methionine residues (approximately four in LMW tau vs six in MMW tau) and quenching of LMW tau radioactivity on autoradiographs due to the abundance of immunoprecipitated immunoglobulin heavy chain protein at the 50 $\mathrm{kDa}$ position. In later postinjection time points, however, the ratio of LMW tau-associated radioactivity to the label in MMW tau progressively diminished, raising the possibility that the separate tau isoforms may have different turnover rates.

\section{Axoplasmic transport kinetics of tau and tubulin are distinct}

Because the ability of tau to bind to microtubules implies a possible functional relationship, we investigated a possible physical association by determining whether or not tau proteins were transported at the same rate as tubulin. From the same groups of ${ }^{35} \mathrm{~S}$-methionine-labeled mice used in the studies described above, we isolated Triton X-100-insoluble cytoskeletons from each of the eight consecutive $1.1 \mathrm{~mm}$ segments of the optic pathway. The radiolabeled cytoskeletal proteins were analyzed by SDS-PAGE and autoradiography. The progressive redistribution of labeled tubulin at 7,15 , and $30 \mathrm{~d}$ postinjection displayed a significantly different pattern from that of the tau proteins at every time point (Fig. 4). An identical rate was observed for cold-insoluble tubulin (data not shown). Tubulin advanced at a rate of $0.1-0.2 \mathrm{~mm} / \mathrm{d}$. This rate corroborates previous estimates of the transport rate of total tubulin (soluble and insoluble) in mouse optic axons as determined in two-dimensional PAGE analyses (Brown et al., 1982; Nixon et al., 1990) and corresponds to the characteristic rate of the slow component A (SCa) transport phase. At $7 \mathrm{~d}$ after isotope injection, about $70 \%$ of the labeled tubulin is still present in the first segment, while more than $80 \%$ of the tau has already moved into the second segment or beyond (Fig. 4). By $30 \mathrm{~d}$ after injection tubulin and tau radioactivity are well separated, tubulin peaks in segments $2-5$, tau in segments 6 and 7. Little if any labeled tau was retained behind the moving transport wave. Thus, a significant proportion of the transported tubulin pool remains unassociated with tau proteins that were synthesized during the same pulse-labeling time interval. This finding implies that tau is not stably associated with axonal microtubules, including those that may be undergoing transport, but rather interacts dynamically with these structures.

\section{Tau proteins are transported at a different rate than other MAPs}

Previously, we showed that MAP1A is transported in retinal ganglion cells at a rate of $0.8-1.0 \mathrm{~mm} / \mathrm{d}$ (Nixon et al., 1990), which is characteristic of the slow component $b(\mathrm{SCb})$ phase of axoplasmic transport. To relate the transport rates of tau proteins to MAP1A and other MAPs in optic axons, we injected groups of mice intravitreously with ${ }^{35} \mathrm{~S}$-methionine, collected optic pathways after 3 and $7 \mathrm{~d}$ and dissected them into eight consecutive $1.1 \mathrm{~mm}$ segments. Proteins in the $100,000 \times g$ supernatant fractions from the individual segments were each assembled with taxol to yield pellet fractions enriched in microtubules and associated proteins and a remaining supernatant fraction of soluble proteins that did not assemble with tubulin. Analyses of these fractions by SDS-PAGE and autoradiography demonstrated peaks of radiolabeled MAPs advancing from segment 2 at $3 \mathrm{~d}$ to segment 6 by $7 \mathrm{~d}$ (Fig. 5), indicating a transport rate of 0.8 $1.0 \mathrm{~mm} / \mathrm{d}$ for these proteins. Each of the major radiolabeled MAPs, including those at $118 \mathrm{kDa}$ and $160 \mathrm{kDa}$, displayed identical kinetics, which were the same as those previously reported for MAP1A and other SCb proteins in optic axons.

Regression analysis was used to demonstrate that the peak values obtained from different postinjection timepoints in this and previous studies for tubulin (Nixon et al., 1990), tau, and other MAPs, including MAP1A (Nixon et al., 1990) represent 


\section{DAY}
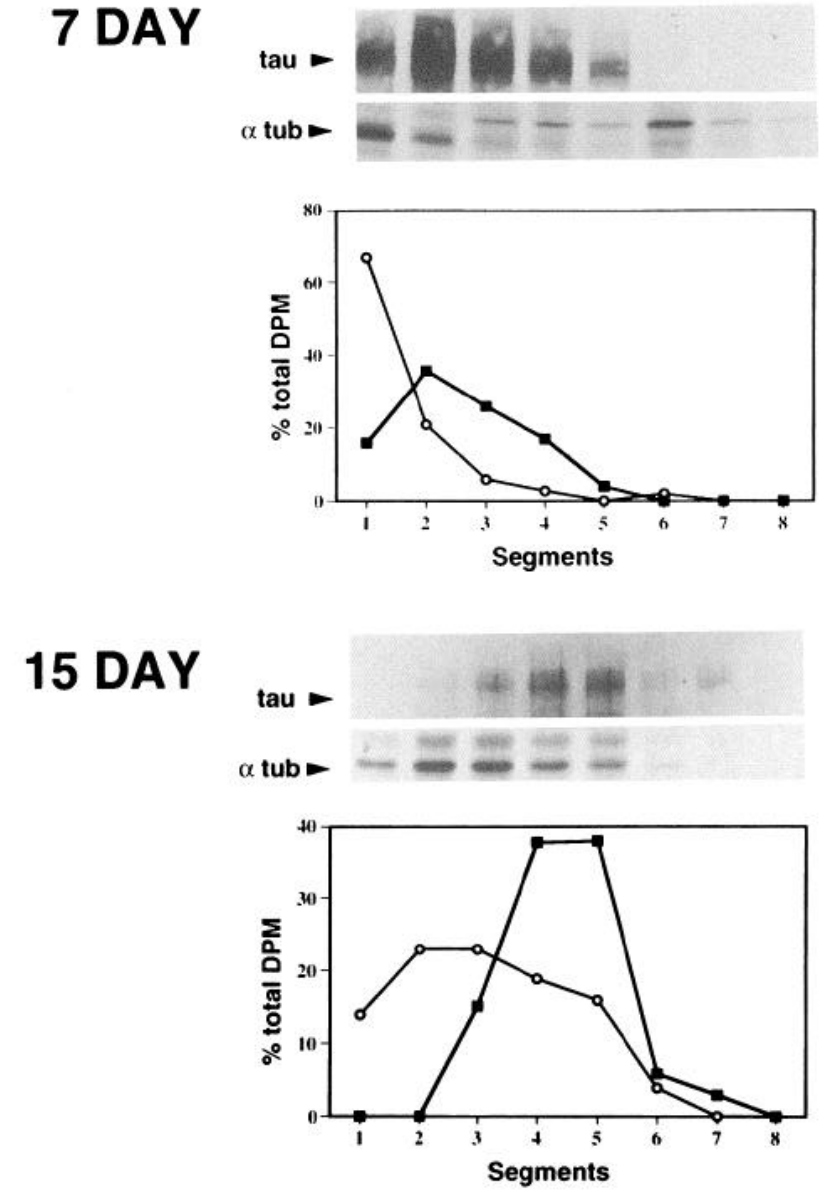

30 DAY
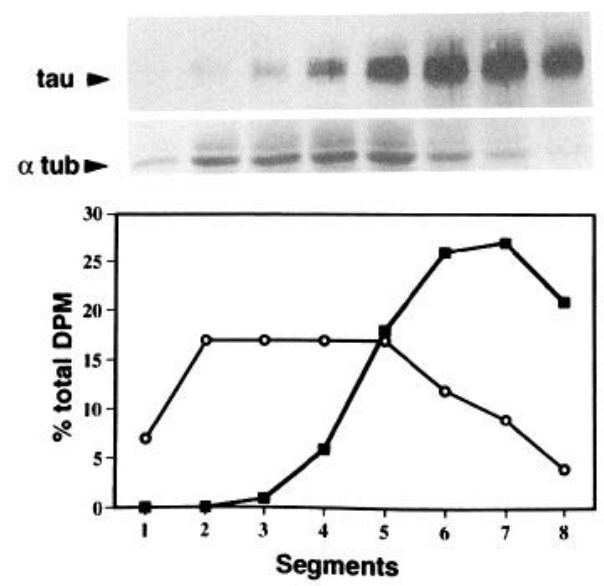

Figure 4. Comparison of the distributions of radiolabeled tau and tubulin in eight consecutive axonal segments at 7, 15, and $30 \mathrm{~d}$ after intravitreous injection of ${ }^{35} \mathrm{~S}$-methionine. MMW tau patterns from immunoprecipitated proteins were obtained after 5-15\% SDS PAGE, electroblotting, and autoradiography of the nitrocellulose membranes. Tubulin in cytoskeleton fractions from the same segments were separated by $5-15 \%$ SDS-PAGE, and autoradiograms of the dried gels were obtained. The graphs depict densitometric analyses of these axoplasmic transport distribution profiles for tau and tubulin at the different time points. Note the different translocation velocities for the peak of the tau and tubulin waves. The arrow in the cytoskeleton fraction at day 7 indicates an unidentified protein that moves with the $\mathrm{SCb}$ wave of transport. significantly different rates of transport irrespective of possible minor differences in time of entrance of the proteins into the axons (Fig. 6). Tau proteins moved in the optic axons at the rate of $0.2-0.4 \mathrm{~mm} / \mathrm{d}$, while tubulin was transported at $0.1-0.2 \mathrm{~mm} / \mathrm{d}$ and other MAPs, including MAP1A, translocated at $0.8-1.0$ $\mathrm{mm} / \mathrm{d}$. Alternative calculations based on values for either the trailing or leading edge of the waves at the different time points or based on the movement of the median point of the wave, showed comparable differences between the transport of tau and tubulin in confirmation of the data in Figure 6 (results not shown).

\section{Discussion}

Tau proteins and other MAPs interact reversibly with microtubules in vitro (Olmsted et al., 1989; Yamauchi et al., 1993; Hirokawa, 1994), but experimental evidence for these interactions in vivo has not been previously presented. Limited existing literature on the behavior of tau in vivo, in fact, suggests that associations of tau with axonal microtubules are stable over the many weeks of axonal transport, implying a relatively static picture of microtubule dynamics in axons of mature neurons (Tytell et al., 1984). Our results support an alternative, more dynamic picture by providing, for the first time, unequivocal evidence for the identity of in vivo radiolabeled tau proteins and showing that the distinct transport rates for tubulin and tau proteins are inconsistent with a stable association between the bulk of axonal microtubules and tau in vivo.

\section{Identity of tau isoforms undergoing axoplasmic transport}

A single previous study has reported on the axonal transport of putative tau isoforms in guinea pig optic axons (Tytell et al., 1984). The authors described two proteins in the LMW tau range, and none in the range of the MMW tau, which we find is a major tau isoform in optic axons. Both proteins were transported at the same rate as tubulin and were the only MAPs found to be axonally transported. These putative tau proteins were major radiolabeled proteins in total homogenates from optic axons dissected $50 \mathrm{~d}$ after isotope injection. We observed, however, that radiolabeled tau proteins in similar total homogenates are undetectable in the presence of the many other heavily radiolabeled bands in this region of the gel. Even after enrichment by heat treatment or cycles of microtubule assembly and disassembly, radiolabeled tau bands were difficult to distinguish from other more heavily labeled proteins. Quantitative immunoprecipitation of the tau proteins from enriched fractions prepared from large numbers of mice was necessary to monitor their transport rate. Proteins in rat optic nerve very similar in molecular weight and transport rate to the proteins described by Tytell et al. (1984) have been identified as intermediate filament proteins associated with the Triton-insoluble cytoskeleton (Monaco et al., 1985). Also, we have observed a soluble major labeled protein in mouse axons that is transported at the same rate as tubulin, but is not tau based on its slightly higher molecular weight and lack of cross-reactivity with a panel of anti-tau antibodies (unpublished data). Species differences are unlikely to be a significant factor because the tau isoforms in rat and mouse optic pathways are similar in molecular weight. We therefore must reason that without the necessary immunological characterization of tau, the previous report on tau transport (Tytell et al., 1984) is not conclusive. 
A

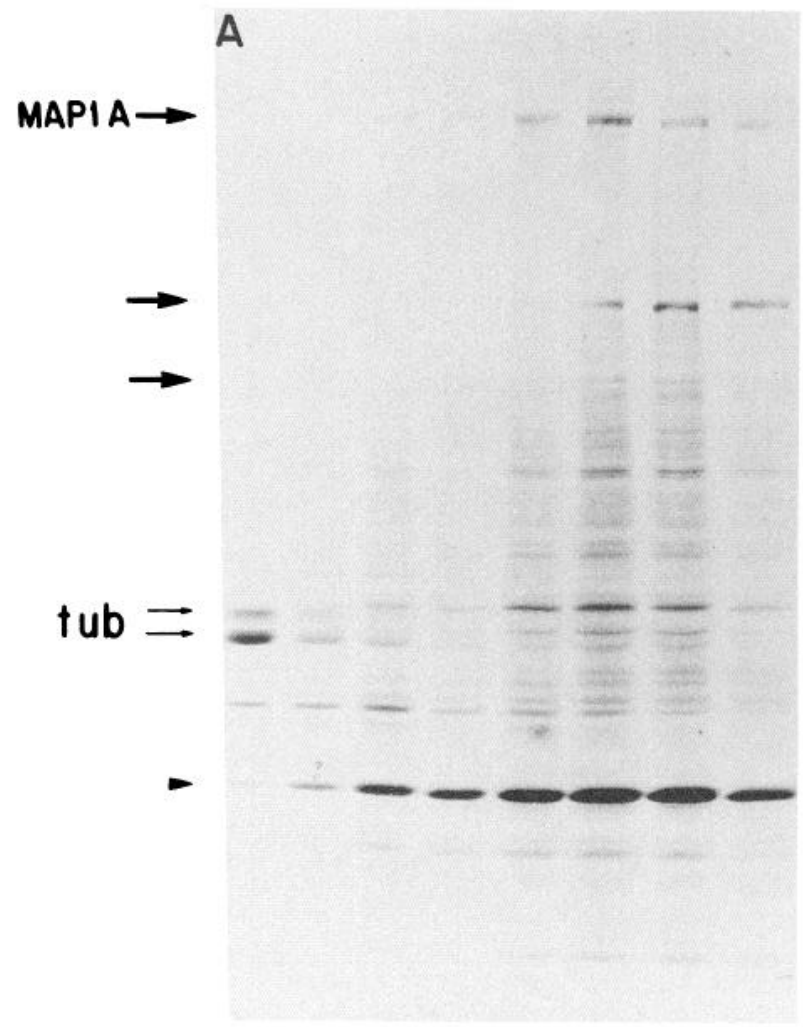

B

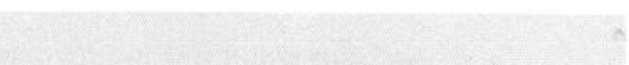

$-210$

$-130$

$-94$

68

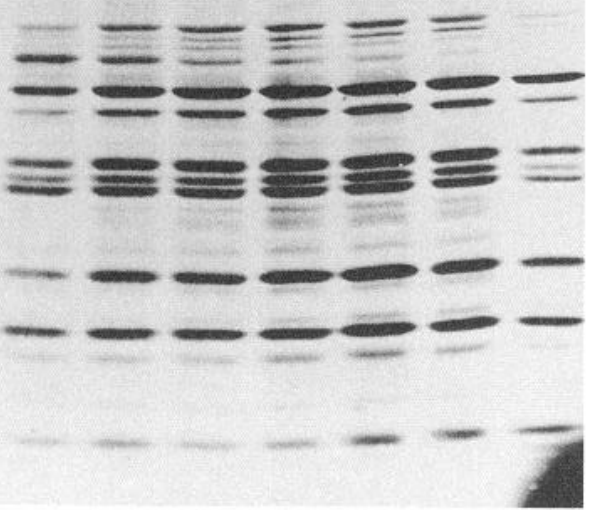

43

Figure 5. Distribution of radiolabeled protein in the taxol assembled microtubule pellet $(A)$ and the nonmicrotubule supernatant $(B)$ along consecutive $1.1 \mathrm{~mm}$ segments of the optic nerve and optic tract obtained $7 \mathrm{~d}$ after injecting mice intravitreally with ${ }^{35} \mathrm{~S}$-methionine. Note several proteins (arrows), including MAP1A, that are present in the microtubule pellet and absent in the supernatant. These MAPs have moved into segments 6 and 7 indicating a transport rate of $0.8-1.0 \mathrm{~mm} / \mathrm{d}$ which is clearly different from tubulin that has only moved into segment 1 and 2 at a rate of $0.1-0.2 \mathrm{~mm} / \mathrm{d}$. Note also for reference a strongly labeled unidentified protein at approximately $30 \mathrm{kDa}(\mathrm{arrowhead})$ that migrates at the rate of $0.8-1.0 \mathrm{~mm} / \mathrm{d}$ and that is present in both the supernatant and pellet fractions.

Figure 6. Regression analyses of the movement of the transport peaks of MAP1A, tubulin and tau as a function of time after intravitreal injection of radiolabeled amino acids. Data from this and previous studies (Nixon et al., 1990) were combined (error bars indicate SDs on the mean values for the different time points). Statistical analysis (SAS) showed that the $99 \%$ confidence intervals for the slopes were not overlapping.

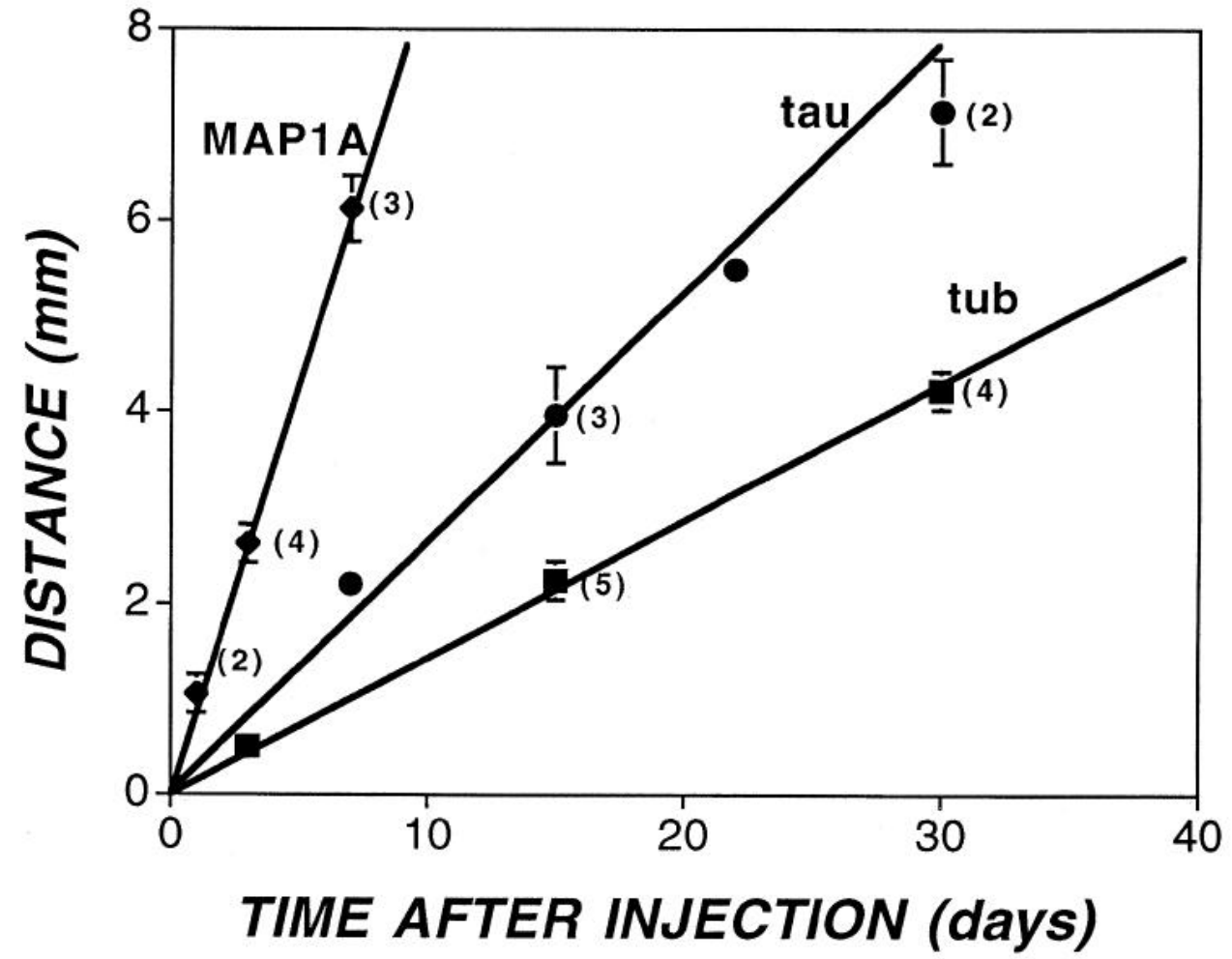




\section{Heterogeneity of axonally transported tau isoforms: possible} functions

The LMW tau proteins, with an apparent size of 50-70 kDa, are the tau isoforms typically isolated from brain tissue, but an additional, substantially larger isoform of $90-100 \mathrm{kDa}$, termed MMW tau, has also been identified in optic nerve (Taleghany and Oblinger, 1992). This isoform is slightly smaller than the $110 \mathrm{kDa}$ HMW ("big") tau, abundant in the PNS (Peng et al., 1986; Georgieff et al., 1991; Oblinger et al., 1991). We have observed a similar pattern of LMW and MMW tau isoforms in the mouse optic pathway. The ratio of MMW/LMW in optic nerves was much higher than that in total retinal extracts. Given the contribution of intraretinal portions of optic axons to the retinal pool of MMW tau, it may be cxpcetcd that interncurons of the retina contain little, if any, MMW tau. One clear difference between ganglion cells and other retinal neurons is the length and size of its axons. This finding, taken together with the presence of HMW tau in long peripheral axons, suggests that the size of the tau proteins is more related to axon length or caliber than to its location within the nervous system. Therefore, in addition to its traditional microtubule stabilizing role, big tau isoforms may fulfill other functions such as maintaining the caliber of large axons through interactions with other cytoskeletal elements. In this regard, the significantly lower amounts of MMW tau observed in the most proximal $1 \mathrm{~mm}$ segment of the optic pathway are reminiscent of a similar nonuniform distribution of neurofilaments along optic axons, which reflects different cytoskeleton dynamics in this specialized axon region (Nixon et al., 1994). The establishment of a larger stationary network of neurofilaments more distally along these axons in association with an expansion of caliber may increase the need for these larger tau isoforms.

The sequence of MMW tau is presently not known. The HMW tau isoform present in the murine neuroblastoma N115 differs from adult LMW tau by having two additional exons; exon 4A, which contains 237 amino acid residues, and exon 6 , which adds 66 extra residues (Couchie et al., 1992). The MMW tau in mouse optic pathway can be immunostained with a polyclonal antisenum raised against recombinant exon $4 \mathrm{~A}$ sequences from rat big tau, which does not cross-react with LMW tau isoforms (results not shown). Based on the slightly smaller size of MMW tau compared to HMW tau, we anticipate that MMW tau lacks exon 6 (or another small exon).

\section{The transport rate for tau is distinctive}

Although tau and MAP1A share certain biologic properties, they exhibited different transport kinetics, which has functional implications. Tau and MAP $1 \mathrm{~A}$ have different microtubule binding domains and bind to distinct sites on microtubules (Hirokawa et al., 1988b). In addition, they display different stoichiometries of binding to tubulin at levels of ligand saturation (Hirokawa et al., $1988 \mathrm{~b}$ ), though their relative binding affinities are not known. We previously showed that the bulk of the pulse-radiolabeled MAP1A translocated at a rate of $0.8-1.0 \mathrm{~mm} / \mathrm{d}$ (Nixon et al., 1990). The rapid movement of one pool of MAP1A at or close to the maximum for slow axonal transport in this system, implies that, if this pool interacts with microtubules during transport, interactions are very transient. A fraction of labeled MAP1A, however, is retained for at least $120 \mathrm{~d}$ after isotope administration (Nixon et al., 1990), which reflects a subpopulation that may interact very stably with stationary microtubules or other resident axonal structures (Hoffman et al., 1992; Watson et al., 1993; Okabe and Hirokawa, 1992; Hirokawa, 1994). Under steady-state conditions, this stable pool of MAP1A is estimated to be one-third or more of the total MAP1A pool in axons. The existence of this pool could explain how long-term functional associations develop between MAP1A and microtubules despite a 5-10-fold faster movement of the bulk of MAP1A compared to tubulins. Unlike MAP1A, the main wave of labeled tau contains a minimal trailing component indicating that the entire tau population behaves as a single kinetic pool during transport, which migrates at a rate of $0.2-0.4 \mathrm{~mm} / \mathrm{d}$. The movement of tau ahead of labeled tubulins implies that interactions with microtubules are dynamic and of shorter duration than those of the MAP1A subpopulation that is retained in axons. We propose that repetitive association and dissociation of tau with stationary microtubules retards its net translocation along axons relative to that of the bulk of newly synthesized MAPs, including MAPIA, which move $0.8-1.0 \mathrm{~mm} / \mathrm{d}$.

The possibility can not be cxcluded that the distinct rates for tau and tubulin reflect the absence of a functional interaction between the two proteins in vivo. Existing in vitro data, however, strongly suggest otherwise (Weingarten et al., 1975; Witman et al., 1976; Cleveland et al., 1977a; Sandoval and Vandekerckhove, 1981; Drubin and Kirschner, 1986; Ennulat et al., 1989). Also, we cannot entirely rule out the possibility that tau within the trailing edge of its transport wave is associated stably with tubulin in the leading edge of its transport wave because separation of the tubulin and tau waves is not complete before the latter reaches the distal end of the optic pathway. The fact that the separation between 7 and $30 \mathrm{~d}$ progressively increases makes this possibility unlikely.

\section{Functional implications of separate transport rates for tau and} tubulin

Our findings indicate that only a fraction of the total M $\Lambda \mathrm{P}$ pool is bound to microtubules at any given time and that the stabilizing functions of tau are highly dynamic. In this regard, axonal microtubules in growing axons in vitro have been previously shown to have a labile domain situated at the plus end of a stable domain (Baas and Black, 1990). Microinjected biotinylated tubulin moving along axons of PC12 cells incorporate preferentially at the plus ends, presumably within these labile domains (Okabe and Hirokawa, 1988). In cultured rat sympathetic neurons, microtubules composed nearly entirely of labile domains predominate at the distal end of the growing axon (Ahmad et al., 1993). These observations suggest that, at least in growing axons, the assembly of microtubule polymer is highly dynamic along the length of the axon and particularly near the advancing growth cone. Our in vivo results, which reflect a cycling of tau on and off microtubules during axonal transport, are consistent with a high degree of microtubule plasticity even in axons that have established their connections and achieved mature size.

It has recently been emphasized that dynamic instability of microtubules may be particularly advantageous in growing axons as they search in space for their target (Holy and Leibler, 1994). Continued dynamic instability within fully mature axons implies that the capability for local reorganization of the cytoskeleton in response to physiological stimuli is preserved. It is increasingly being recognized that the cytoskeletal architecture of mature axons, like those of retinal ganglion cells, is highly ordered but nonuniform and regionally specialized along the length of these axons (Nixon and Logvinenko, 1986; Nixon et 
al., 1994). Dynamic assembly mechanisms may be required to facilitate the local incorporation and rearrangements of structural elements within this regionally specialized cytoskeleton suprastructure along axons and synapses.

\section{References}

Aamodt EJ, Williams Jr RC (1984) Microtubule-associated proteins connect microtubules and neurofilaments in vitro. Biochemistry 23 : 6023-6031.

Ahmad FJ, Pienkowski TP, Baas PW (1993) Regional differences in microtubule dynamics in the axon. J Neurosci 13:856-866.

Baas PW, Black MM (1990) Individual microtubules in the axon consist of domains that differ in both composition and stability. J Cell Biol 111:495-509.

Binder LI, Frankfurter A, Rebhun LI (1985) The distribution of tau in the mammalian central nervous system. J Ccll Biol 101:1371-1378.

Brandt R, Lee G (1993) The balance between tau protein's microtubule growth and nucleation activities: implications for the formation of axonal microtubules. J Neurochem 61:997-1005.

Brown BA, Nixon RA, Marotta CA (1982) Posttranslational processing of alpha-tubulin during axoplasmic transport in CNS axons. $J$ Cell Biol 94:159-164.

Brugg B, Matus A (1991) Phosphorylation determines the binding of microtubule-associated protein 2 (MAP2) to microtubules in living cells. J Cell Biol 114:735-743.

Chen J, Kanai Y, Cowan NJ, Hirokawa N (1992) Projection domains of MAP2 and tau determine spacings between microtubules in den drites and axons. Nature 360:674-677.

Chiu FC, Norton WT (1982) Bulk preparations of CNS cytoskeleton and the separation of individual neurofilament proteins by gel filtration: dye-binding characteristics and amino acid compositions. J Neurochem 39:1251-1260.

Cleveland DW, Hwo SY, Kirschner MW (1977a) Physical and chemical properties of purified tau factor and the role of tau in microtubule assembly. J Mol Biol 116:227-247.

Cleveland DW, Hwo SY, Kirschner MW (1977b) Purification of tau, a microtubule-associated protein that induces assembly of microtubules from purified tubulin. J Mol Biol 1 16:207-225.

Couchie D, Mavilia C, Georgieff IS, Liem RK, Shelanski ML, Nunez J (1992) Primary structure of high molecular weight tau present in the peripheral nervous system. Proc Natl Acad Sci USA 89:43784381.

Correas I, Diaz-Nido J, Avila J (1992) Microtubule-associated protein tau is phosphorylated by protein kinase $\mathrm{C}$ on its tubulin binding domain. J Biol Chem 267:15721-15728.

Dotti CG, Banker GA, Binder LI (1987) The expression and distribution of the microtubule-associated proteins tau and microtubule-associated protein 2 in hippocampal neurons in the rat in situ and in cell culture. Neuroscience 23:121-130.

Drechsel DN, Hyman AA, Cobb MH, Kirschner MW (1992) Modulation of the dynamic instability of tubulin assembly by the microtubule-associated protein tau. Mol Biol Cell 3:1141-1154.

Drubin DG, Kirschner MW (1986) Tau protein function in living cells. J Cell Biol 103:2739-2746.

Drubin DG, Feinstein SC, Shouter EM, Kirschner MW (1985) Nerve growth factor-induced neurite outgrowth in PC12 cells involves the coordinate induction of microtubule assembly and assembly-promoting factors. J Cell Biol 101:1799-1807.

Ennulat DJ, Liem RK, Hashim GA, Shelanski ML (1989) Two separate 18 -amino acid domains of tau promote the polymerization of tubulin. J Biol Chem 264:5327-5330.

Friede RL, Samorajski T (1970) Axon caliber related to neurofilaments and microtubules in sciatic nerve fibers of rats and mice. Anat Rec 167:379-387.

Georgieff IS, Liem RK, Mellado W, Nunez J, Shelanski ML (1991) High molecular wcight tau: preferential localization in the peripheral nervous system. J Cell Sci 100:55-60.

Goedert M (1993) Tau protein and the neurofibrillary pathology of Alzheimer's disease. Trends Neurosci 16:460-465.

Hirokawa N (1994) Microtubule organization and dynamics dependent on microtubule-associated proteins. Curr Opin Cell Biol 6:74-81.

Hirokawa N, Hisanaga S, Shiomura Y (1988a) MAP2 is a component of crossbridges between microtubules and neurofilaments in the neu- ronal cytoskeleton: quick-freeze, deep-etch immunoelectron microscopy and reconstitution studies. J Neurosci 8:2769-2779.

Hirokawa N, Shiomura Y, Okabe S (1988b) Tau proteins: the molecular structure and mode of binding on microtubules. J Cell Biol 107: 1449-1459.

Hoffman PN, Lopata MA, Watson DF, Luduena RF (1992) Axonal transport of class II and III beta-tubulin: evidence that the slow component wave represents the movement of only a small fraction of the tubulin in mature motor axons. J Cell Biol 119:595-604.

Holy TE, Leibler S (1994) Dynamic instability of microtubules as an efficient way to search in space. Proc Natl Acad Sci USA 91:56825685 .

Joachim CL, Morris JH, Kosik KS, Selkoe DJ (1987) Tau antisera recognize neurofibrillary tangles in a range of neurodegenerative disorders. Ann Neurol 22:514-520.

Kanai Y, Takemura R, Oshima T, Mori H, Ihara Y, Yanagisawa M, Masaki T, Hirokawa N (1989) Expression of multiple tau isoforms and microtubule bundle formation in fibroblasts transfected with a single tau cDNA. J Cell Biol 109:1173-1184.

Kosik KS (1993) The molecular and cellular biology of tau. Brain Pathol 3:39-43.

Kosik KS, Orecchio LD, Binder L, Trojanowski JQ, Lee WM, Lee G (1988) Epitopes that span the tau molecule are shared with paired helical filaments. Neuron 1:817-825.

Laemmli UK (1970) Cleavage of structural proteins during the assembly of the head of bacteriophage T4. Nature 227:680-685.

Leterrier JF, Liem RK, Shelanski ML (1982) Interactions between neurofilaments and microtubule-associated proteins: a possible mechanism for intraorganellar bridging. J Cell Biol 95:982-986.

Mandelkow EM, Mandelkow E (1993) Tau as a marker for Alzheimer's disease. Trends Biochem Sci 18:480-483.

Matus A (1988) Microtubule-associated proteins: their potential role in determining neuronal morphology. Annu Rev Neurosci 11:29-44.

Matus A (1991) Microtubule-associated proteins and neuronal morphogenesis. J Cell Sci Suppl 15:61-67.

Matus A (1994) Stiff microtubules and neuronal morphology. Trends Neurosci 17:19-22.

Mercken M, Vandermeeren M, Lubke U, Six J, Boons J, Vanmechelen E, Van de Voorde A, Gheuens J (1992) Affinity purification of human tau proteins and the construction of a sensitive sandwich enzyme-linked immunosorbent assay for human tau detection. J Neurochem 58:548-553.

Mitchison T, Kirschner M (1984) Dynamic instability of microtubule growth. Nature 312:237-242.

Monaco S, Autilio-Gambetti L, Zabel D, Gambetti P (1985) Giant axonal neuropathy: acceleration of neurofilament transport in optic axons. Proc Natl Acad Sci USA 82:920-924.

Murphy DB, Borisy GG (1975) Association of high-molecular-weight proteins with microtubules and their role in microtubule assembly in vitro. Proc Natl Acad Sci USA 72:2696-2700.

Nixon RA (1980) Protein degradation in the mouse visual system. I. Degradation of axonally transported and retinal proteins. Brain Res 200:69-83.

Nixon RA, Logvinenko KB (1986) Multiple fates of newly synthesized neurofilament proteins: evidence for a stationary neurofilament network distributed nonuniformly along axons of retinal ganglion cell neurons. J Cell Biol 102:647-659.

Nixon RA, Brown BA, Marotta CA (1982) Posttranslational modification of a neurofilament protein during axoplasmic transport: implications for regional specialization of CNS axons. J Cell Biol 94:150158.

Nixon, RA, Fischer I, Lewis SE (1990) Synthesis, axonal transport, and turnover of the high molecular weight microtubule-associated protein MAP 1A in mouse retinal ganglion cells: tubulin and MAP 1A display distinct transport kinetics. J Cell Biol 110:437-448.

Nixon RA, Paskevich PA, Sihag RK, Thayer CY (1994) Phosphorylation on carboxyl terminus domains of neurofilament protcins in retinal ganglion cell neurons in vivo: influences on regional neurofilament accumulation, interneurofilament spacing, and axon caliber. $\mathrm{J}$ Cell Biol 126:1031-1046.

Oblinger MM, Argasinski A, Wong J, Kosik KS (1991) Tau gene expression in rat sensory neurons during development and regeneration. J Neurosci 11:2453-2459.

Okabe S, Hirokawa N (1988) Microtubule dynamics in nerve cells: 
analysis using microinjection of biotinylated tubulin into PC12 cells. J Cell Biol 107:651-664.

Okabe S, Hirokawa N (1992) Differential behavior of photoactivated microtubules in growing axons of mouse and frog neurons. J Cell Biol 117:105-120.

Olmsted JB (1991) Non-motor microtubule-associated proteins. Curr Opin Cell Biol 3:52-58.

Olmsted JB, Stemple DL, Saxton WM, Neighbors BW, McIntosh JR (1989) Cell cycle-dependent changes in the dynamics of MAP 2 and MAP 4 in cultured cells. J Cell Biol 109:211-223.

Peng I, Binder LI, Black MM (1986) Biochemical and immunological analyses of cytoskeletal domains of neurons. J Cell Biol 102:252262.

Saitua F, Alvarez J (1988) Do axons grow during adulthood? A study of caliber and microtubules of sural nerve axons in young, mature, and aging rats. J Comp Neurol 269:203-209.

Sakaguchi T, Okada M, Kilamura T, Kawasaki K (1993) Reduced diameter and conduction velocity of myelinated fibers in the sciatic nerve of a neurofilament-deficient mutant quail. Neurosci Lett 153: 65-68.

Sandoval IV, Vandekerckhove JS (1981) A comparative study of the in vitro polymerization of tubulin in the presence of the microtubuleassociated proteins MAP2 and tau. J Biol Chem 256:8795-8800.

Scherson T, Kreis TE, Schlessinger J, Littauer UZ, Borisy GG, Geiger B (1984) Dynamic interactions of fluorescently labeled microtubuleassociated proteins in living cells. J Cell Biol 99:425-434.

Scott CW, Klika AB, Lo MM, Norris TE, Caputo CB (1992) Tau protein induces bundling of microtubules in vitro: comparison of different tau isoforms and a tau protein fragment. J Neurosci Res 33:1929.

Shea TB, Beermann ML, Nixon RA, Fischer 1 (1992) Microtubuleassociated protein tau is required for axonal neurite elaboration by neuroblastoma cells. J Neurosci Res 32:363-374.
Sloboda RD, Dentler WL, Rosenbaum JL (1976) Microtubule-associated proteins and the stimulation of tubulin assembly in vitro. Biochemistry $15: 4497-4505$.

Takemura R, Okabe S, Umeyama T, Kanai Y, Cowan NJ, Hirokawa N (1992) Increased microtubule stability and alpha tubulin acetylation in cells transfected with microtubule-associated proteins MAP1B, MAP2 or tau. J Cell Sci 103:953-964.

Taleghany N, Oblinger MM (1992) Regional distribution and biochemical characteristics of high molecular weight tau in the nervous system. J Neurosci Res 33:257-265.

Tucker RP (1990) The roles of microtubule-associated proteins in brain morphogenesis: a review. Brain Res Brain Res Rev 15:101-120.

Tytell M, Brady ST, Lasek RJ (1984) Axonal transport of a subclass of tau proteins: evidence for the regional differentiation of microtubules in neurons. Proc Natl Acad Sci USA 81:1570-1574.

Vallee RB (1982) A taxol-dependent procedure for the isolation of microtubules and microtubule-associated proteins (MAPs). J Cell Biol 92:435-442.

Watson DF, Glass JD, Griffin JW (1993) Redistribution of cytoskeletal proteins in mammalian axons disconnected from their cell bodies. $J$ Neurosci 13:4354-4360.

Weingarten MD, Lockwood AH, Hwo SY, Kirschner MW (1975) A protein factor essential for microtubule assembly. Proc Natl Acad Sci USA 72:1858-1062.

Wiche G, Oberkanins C, Himmler A (1991) Molecular structure and function of microtubule-associated proteins. Int Rev Cytol 124:217273.

Witman GB, Cleveland DW, Weingarten MD, Kirschner MW (1976) Tubulin requires tau for growth onto microtubule initiating sites. Proc Natl Acad Sci USA 73:4070-4074.

Yamauchi PS, Flynn GC, Marsh RL, Purich DL (1993) Reduction in microtubule dynamics in vitro by brain microtubule-associated proteins and by a microtubule-associated protein- 2 second repeated sequence analogue. J Neurochem 60:817-826. 